\title{
Modeling the Interdependence in Household Residence and Workplace Choices
}

1. Paul Waddell (Corresponding Author)

Evans School of Public Affairs

University of Washington

Seattle, WA 98195-3055

Phone: $\quad+1.206 .221 .4161$

Fax: $\quad+1.206 .685 .9597$

E-mail:pwaddell@u.washington.edu

2. Chandra Bhat

Department of Civil, Architectural, and

Environmental Engineering

University of Texas at Austin

Ernest Cockrell Jr. Hall, 6.810

Austin, Texas 78712

Phone: $\quad+1.512 .471 .4535$

Fax: $\quad+1.512 .475 .8744$

E-mail: bhat@mail.utexas.edu

3. Naveen Eluru

Department of Civil, Architectural, and

Environmental Engineering

University of Texas at Austin

Ernest Cockrell Jr. Hall, 6.810

Austin, Texas 78712

Phone: $\quad+1.512 .968 .1259$

Fax: $\quad+1.512 .475 .8744$

E-mail: naveeneluru@mail.utexas.edu
4. Liming Wang

Dept of Urban Design and Planning

College of Architecture \& Urban Planning University of Washington

Seattle, WA 98195-5740

Phone: $\quad+1.206 .616 .4499$

Fax: $\quad+1.206 .685 .9597$

Email: 1mwang@u.washington.edu

5. Ram M. Pendyala

Department of Civil and Environmental

Engineering

Arizona State University

Room ECG252

Tempe, AZ 85287-5306

Phone: $\quad+1.480 .727 .9164$

Fax: $\quad+1.480 .965 .0557$

Email: ram.pendyala@asu.edu

Revised November 2006

Word Count: 6080 text +6 (Tables) x $250=7580$

Submitted for Presentation and Publication to the Transportation Research Board 


\begin{abstract}
Models of residential and workplace location choice prevalent in the literature often assume that one choice dimension is exogenous to the other. In our view, a broad and uniform assumption that one choice dimension is exogenous and influences the other is too strong to use as the foundation for current behavioral research or applied policy analysis. We seek to examine the interdependence of residence and workplace choices and to develop a novel approach to modeling these choice dependencies. Two problems related to such joint modeling efforts are addressed in this paper. First, through a latent market segment modeling approach, the paper offers a methodology for accommodating different sequential decision-making processes that may be present in the population, i.e., residential location may be chosen first and influence workplace location for one segment and vice versa. Second, the modeling approach offers a means of overcoming the exploding choice set problem when attempting to model multidimensional choice phenomena. The overall aim of the work is to model the structure of the interdependency between the choices that a household makes with respect to residence location, and the workplace choices of the workers in the household, in the context of an integrated activity location and travel forecasting framework. This paper presents a joint model of residence location and workplace using an activity-based travel survey collected in the Puget Sound region of Washington in 1999, using a novel adaptation of recent methods for incorporating latent market segmentation within discrete choice models.
\end{abstract}

Keywords: Residential location, workplace location, latent segmentation, discrete choice, behavioral decision-making, multi-dimensional choices 


\section{INTRODUCTION}

Traditional urban economic theory and the vast majority of empirical work in urban modeling treats the residence location choice as conditional on an exogenous choice of workplace. Some empirical work, on the other hand, including the workplace destination choice models embedded in metropolitan transportation models, assume that residence location is predetermined when predicting the workplace location choice. All of this work treats the residence and workplace choices as though one is exogenous and influences the other. More importantly, such endeavors assume that the same conditional choice process applies to the entire population under study. The assumption that one choice dimension (i.e., either residence or workplace choice) is exogenous and influences the other for the entire population without any regard for the possibility that a reverse choice process may be in vogue for at least a segment of the population is, in our view, too strong to use as the foundation for current behavioral research or applied policy analysis. We seek to examine the interdependence of residence and workplace choices and to develop a novel approach to modeling these choice dependencies that overcomes two inter-related challenges. First, there may be unobserved heterogeneity in the population with different market segments following different decision processes unknown to the analyst. Second, when modeling multi-dimensional choice phenomena, choice sets may explode in size due to the curse of dimensionality. If there are 1000 possible location choices, then there are $1000 \times 1000=1,000,000$ possible joint residence-workplace location choices.

The importance of this topic in the context of travel behavior is clear. If the entire population is assumed to follow a uniform choice-making process when in fact there is unobserved heterogeneity in the decision-making process, then patterns of substitution among alternatives will potentially be significantly biased, thereby distorting the policy evaluation of transportation investments or land use regulations. There is also a potential to contribute to the advancement of activity-based travel modeling with this work. Workplace choices have been addressed in aggregate travel models as though they were daily choices, predicted within the destination choice model for the home-based work purpose. In activity-based models, however, there is an opportunity to structure workplace choice, and its interdependence with residence location, as a long-term set of choices that condition daily activity and travel behavior. To date, however, no work has yet been reported that estimates the structure of the interdependency between the choices that a household makes with respect to residence location, and the workplace choices of the workers in the household, in the context of an integrated activity location and travel forecasting framework, while overcoming the two challenges noted previously. The paper reduces this gap in the literature by developing a joint model of residence location and workplace using an activity-based travel survey collected in the Puget Sound region of Washington in 1999. The paper develops a novel adaptation of recent methods for incorporating latent market segmentation to predict the mix of latent choice structures of residence and workplace choice (i.e., which choice conditions the other) that may be present in the population. The challenges of dimensionality of the extremely large choice sets that arise in the context of joint residence and workplace location modeling are also addressed by this method, making it tractable for planning and modeling applications.

\section{RESIDENCE AND WORKPLACE CHOICES}

The development of classical urban spatial models such as the mono-centric model $(1,2)$ assume that each household has only one worker, and that the workplace choice is predetermined, or 
exogenous, to residential location choice. While assumptions such as the location of all employment within the central business district have received considerable criticism from theoretical and empirical perspectives since the rise of polycentric urban areas, these two assumptions have been largely ignored in the development and extension of models of urban spatial structure and residential location. Within the realm of operational urban models such as the DRAM/EMPAL models by Putman (3), the NBER/HUDS models by Kain and Apgar (3), the CATLAS/METROSIM models by Anas (5), the TRANUS model by de la Barra (6), and the MEPLAN model by Eschenique (7), the traditional assumptions of workplace being exogenous to models of residential location and households having only one worker have continued to be maintained. More recent operational models, such as UrbanSim, relax the assumption of one worker per household, but still model residential location as being influenced by workplace choice (8).

Remarkably little research has explored the interdependence of workplace choice and residential location, despite the topic being of much interest for more than two decades. Linneman and Graves (9) argued for the interdependence of job search and residence decisions, and Gordon and Vickerman (10) suggested that while the residential and workplace choices may not be simultaneous, some individuals may choose residences on the basis of prior workplace choices, while others may search for jobs on the basis of their current residential location. Efforts to relax the exogenous workplace assumption of the monocentric model have been made by Siegel (11), Simpson (12, 13), Merriman (14), and Waddell (15-17).

In an investigation focusing on the simplifying case of households with only one worker, for which the assumption of exogenous workplace choice is most plausible, Waddell (15) found, using data from the Dallas-Fort Worth metropolitan area, that results from a nested logit model of workplace and residential choice contradicted the assumption of exogenous workplace choice in residential location. The results supported a joint choice of residential location and workplace, which reflects the reality that job change may or may not be accompanied by residential relocation, and residential relocation may occur with or without job change. That study was based on cross-sectional data derived from the 1980 Census Journey to Work, and ultimately used a standard multinomial logit (MNL) specification of the joint choices of residence and workplace, with random sampling of alternatives. The model specification relied on the Independence of Irrelevant Alternatives (IIA) property of the MNL model, but in a spatial model of this type, especially considering the interdependence of residence and workplace, this assumption could easily be violated.

A later study by Waddell, exploring residence and workplace choices using multipleworker households, drew on a panel survey in the Puget Sound region of Washington, but also used a sampling of alternatives approach within the standard MNL framework (16). The analysis of multiple worker households was further extended in a nested choice model of the decision to move and the conditional choice of location, stratified by single- and dual-worker households (17) in the Honolulu metropolitan area, but this research did not directly model workplace choices. Abraham and Hunt (18) used nested logit, and Freedman and Kern (19) used a joint logit model, to analyze residence and workplace choices among multiple worker households. Finally, there is related research on the dynamics of residence and job change and their interdependence that could inform further work on the dynamic aspects of these choices (20, 21).

Recent advances in the modeling of choices using latent market segmentation (e.g., 22) offer a new means to address the difficult analytical problem of modeling the interdependence of 
residence and workplace choices. If we recognize that at any given point of time, some households may be making choices to change residence while remaining in their current employment locations, while others may be changing jobs while retaining their residence, we can represent the interdependence of residence and workplace choices as a mixture of these choice heuristics. This is the strategy we adopt in this paper. Our aim is to develop a latent segmentation approach to empirically estimate the presence of these two choice heuristics in the population, and identify the appropriate contingent choice models of residence location and workplace.

\section{DATA}

The data used in this study is from the Puget Sound region of Seattle, Washington. The 1999 Puget Sound Regional Council (PSRC) Activity Survey, a household activity diary survey covering the four-county metropolitan region, was used to extract relevant household and worker socio-economic and location information. This data was augmented by year 2000 parcel and assessment data from the King County Department of Assessments and by accessibility measures from the Puget Sound Regional Council travel model. A little over 900 traffic analysis zones (TAZ) comprised the residential and work location choice sets. For this analysis, we used households that had one non-home-based worker, since this simplifies the empirical application considerably, and allows the research to focus on development of a new approach to modeling the interdependence of residence and workplace choices. Extension to the case of multiple worker households is conceptually straightforward, but substantially increases computational complexity and is therefore set aside as a subject of future research.

Table 1 provides a summary of selected household characteristics in the survey data used, which included 1823 households with one non-home-based worker. Distributions of household size, household income, vehicle ownership and children are included, and these reveal a concentration of single-person households with no children, although the sample does include families and other types of households. The auto mode is clearly the superior mode of transport in this empirical setting. The average drive-alone home-to-work travel time (assuming every worker in the sample chooses to drive) is 25.8 minutes while the corresponding average transit travel time is considerably larger at 114.5 minutes. These travel time measures are used to incorporate accessibility considerations in the location choice models.

\section{THE MODEL}

In this section, we develop the model specification and our methodology. We begin with a background and then proceed to the model structure.

\section{Background}

A joint residence-workplace location model may be estimated by enumerating all combinations or bundles of residential location and workplace location, and designating each bundle as a discrete choice alternative. If the analyst is willing to assume away any spatial correlation among alternatives, and ignore unobserved sensitivity variations across individuals associated with travel impedance and other spatial measures in the choice process, a simple multinomial logit (MNL) formulation may be used for the joint residence-workplace model. In this situation, the analyst can invoke the Independence from Irrelevant Alternatives (IIA) property of the MNL and resort to a sampling approach to reduce the number of alternatives during estimation. However, recent studies have underscored the need to accommodate spatial correlation and unobserved 
sensitivity variation (or unobserved heterogeneity) effects in spatial location choice modeling (e.g., 23, 24). In such cases, the IIA property is violated, and the analyst cannot resort to sampling (see 25 for a theoretical and empirical exposition of this point).

A problem with the full enumeration approach of all alternatives (which is needed when one considers more advanced models than the MNL, such as the mixed MNL, to accommodate spatial correlation and heterogeneity effects) is that it leads to an explosion in the number of alternatives. For instance, if there are 1000 candidate residential locations and 1000 candidate workplace locations, the total number of alternatives is $10^{6}$. In addition, a mixed MNL approach requires a simulated estimation approach. Thus, if there are $\mathrm{Q}$ decision-makers in the sample for estimation, and if $\mathrm{N}$ simulation draws are used per individual in the estimation, the total number of systematic utility component computations per likelihood function iteration is of the order of $10^{6} \times Q \times N$. Clearly, there is a need for a generic approach that accommodates the jointness in residence and workplace location modeling without the explosion in computation time due to the dimensionality compounding problem.

In this paper, we use a novel latent structure approach to address the dimensionality problem without imposing a structure on the decision process a priori. In particular, we do not pre-specify whether the workplace location is chosen first followed by the residential location, or vice-versa. That is, we retain the joint nature of the residential choice and workplace location problem, without the "curse of dimensionality" arising from a traditional enumeration approach of all residential location-workplace location combinations. In the context of the empirical example provided earlier, the total number of systematic utility component computations per likelihood function iteration is of the order of $2 \times 10^{3} \times \mathrm{Q} \times \mathrm{N}$ in our approach, which is substantially lower than the $10^{6} \times Q \times N$ computation in the full enumeration approach.

The latent structure approach used here has been applied in the context of latent segmentation, where decision-makers are probabilistically assigned to each segment based on their characteristics, and a separate behavioral structure corresponding to systematic sensitivity variations to exogenous variables is estimated for each latent segment (26-29). However, the novelty in the current paper is that the latent structure is being applied not to accommodate differential systematic variable sensitivity across individuals, but to accommodate different decision-making structures (i.e., whether a household first decides on residential location and then on workplace location, or vice versa).

\section{Structure}

The behavioral paradigm that forms the foundation of the modeling approach adopted in this paper is that residence and workplace location choices are made jointly and sequentially. In other words, one choice dimension is assumed to influence the other (thus the joint nature of the relationship). Also, one choice dimension is assumed to precede the other and therefore there are two possible choice processes, one where residential location is chosen first and influences work location, and vice versa. Both of these sequential choice processes are present in the population in a proportion that is unknown to the analyst. This behavioral paradigm is consistent with the body of literature on residence and workplace location choice modeling and offers a mechanism to jointly model these choice phenomena while overcoming the two challenges noted in the introductory section. It is theoretically possible that both of these choices are made simultaneously as an instantaneous bundle (i.e., a residential - work location pair). However, we have adopted a sequential choice paradigm in light of the body of evidence in the literature (where one choice dimension is consistently modeled as a function of the other) and the findings 
reported later in this paper. In practice, one would expect one or the other to precede and influence the other choice dimension. Moreover, in view of the computational challenges associated with the simultaneous treatment of residential and work place location choices, the adoption of a sequential decision-making paradigm as the underlying basis of the modeling approach provides a computationally tractable framework for modeling these choice phenomena jointly while recognizing the presence of unobserved heterogeneity in the population (with respect to decision structures).

In the following formulation, we use the index $q$ for both workers and households because of our focus on one-worker households. We assume a random utility framework as the basis of the household's residential location-workplace location choice, following McFadden (30). Consider the worker $q$ in a household, and let the probability that this individual $q$ chooses workplace location $i$ from the set $C_{q}$ of available workplace locations, conditional on having made the residential location choice first, be given by the following multinomial logit form conditional on $\beta_{q}$ :

$$
P_{q}(i) \mid \text { residence location } k=\frac{e^{\left(\beta_{q}^{\prime} x_{q i k} / \sigma_{w}\right)}}{\sum_{j \in C_{q}} e^{\left(\beta_{q}^{\prime} x_{q j k} / \sigma_{w}\right)}},
$$

where $x_{q i k}$ is a vector of variables associated with workplace location $i$ for individual $q$ residing in residential location $k, \beta_{q}$ is an individual-specific parameter vector to be estimated, and $\sigma_{w}$ is a scale parameter. We allow unobserved heterogeneity across individuals by assuming that the vector $\beta_{q}$ for individual $q$ is a draw from a multivariate normally distributed population distribution $\phi(\beta)$ whose moment parameters are characterized by $\Omega$. Then, the unconditional probability of choosing workplace location $i$, given the choice of residence location $k$, is:

$$
P_{q}(i) \mid \text { residence location } k=\int_{\beta} \frac{e^{\left(\beta^{\prime} x_{q i k} / \sigma_{w}\right)}}{\sum_{j \in C_{q}} e^{\left(\beta^{\prime} x_{q i k} / \sigma_{w}\right)}} \cdot \phi(\beta \mid \Omega) d \beta
$$

Next, the probability that the household $q$ chooses residential location $k$ from the set $D_{q}$ of available residential locations, conditional on having made the workplace location choice first, can be similarly formulated as:

$$
P_{q}(k) \mid \text { workplace } i=\int_{\gamma} \frac{e^{\left(\gamma^{\prime} z_{q k i} / \sigma_{r}\right)}}{\sum_{l \in D_{q}} e^{\left(\gamma^{\prime} z_{q k j} / \sigma_{r}\right)}} \phi(\gamma \mid \Psi) d \gamma
$$

where $z_{q k i}$ is a vector of variables associated with residence location $k$ for individual $q$ whose workplace location is at $i, \gamma$ is a vector drawn from a multivariate normal distribution $\phi(\gamma)$ whose moment parameters are characterized by $\Psi$, and $\sigma_{r}$ is a scale parameter. be:

Finally, let the probability that individual $q$ makes the choice of residence location first

$$
P_{q, \text { residence first }}=\frac{e^{\alpha^{\prime} w_{q}}}{1+e^{\alpha^{\prime} w_{q}}}
$$


where $w_{q}$ is a vector of individual-specific characteristics, and $\alpha$ is a corresponding parameter to be estimated. The probability of individual $q$ making the choice of workplace location first is then given as:

$$
P_{q, \text { workplace first }}=1-P_{q, \text { residence first }}
$$

Of course, we do not know the actual sequence of decision-making. But we can form the unconditional probability of individual $q$ residing in location $k$ and working in zone $i$ as:

$$
P_{q}(i k)=P_{q \text {, residence first }} \times\left[P_{q}(i) \mid \text { residence } k\right]+P_{q \text {, workplace first }} \times\left[P_{q}(k) \mid \text { workplace } i\right]
$$

The $\log$-likelihood function for the estimation of the parameters $\beta, \alpha, \Omega, \Psi, \sigma_{w}$, and $\sigma_{r}$ may be written as:

$$
L=\sum_{q=1}^{Q} \delta_{q i k} \log P_{q}(i k)
$$

where $\delta_{q i k}=1$ if individual $q$ resides in $k$ and works in $i$, and 0 otherwise.

The reader will note that $\sigma_{w}$ and $\sigma_{r}$ are not estimable in general. However, if at least one of the coefficients in $\beta$ and $\gamma$ are constrained to be equal in both mean value and standard deviation, then one can normalize one of the scale parameters to 1 and estimate the ratio of the two scale parameters. In the current model, we constrain the mean sensitivity and unobserved heterogeneity in the response to the commute-related variable to be equal since this variable is defined by the combination of residences and workplaces, and the sensitivity to commute time should not vary based on which decision is made first. Although this assumption constitutes a logically plausible identification restriction, testing its veracity is a worthy future research idea.

A final note on the model structure - the share of individuals making the residence location choice first can be obtained as $\sum_{q} P_{q \text {, residence first }}$, and the share of individuals making the workplace location choice first can be obtained as $\sum_{q} P_{q, \text { workplace first }}$.

\section{Specification}

The model structure involves three choice equations, one for the residence choice, one for workplace, and one for the sequence of these choices. In specifying the residence location choice, variables were selected based on prior work of the authors in modelling residential location, and on other literature. The intent was to provide a parsimonious specification for purposes of exploring the interdependence of residence and workplace, rather than a comprehensive specification.

Three kinds of variables were used in the residence location choice specification: neighborhood attributes (with neighborhoods approximated by a little over 900 zones), accessibility variables, and interactions of household and alternative characteristics. The neighborhood attributes included in the model estimation were meant to reflect a combination of key characteristics that influence residential choices, such as the average income of the neighborhood, the density of employment and of population, and a size variable reflecting the size of the housing stock available for location in the neighborhood.

Accessibility is clearly of interest in both the residence and workplace choices, and is in fact largely determined by these two choices. We focus on the measurement of the home to work commute, by mode of travel, using zone to zone skims from the travel model - for the 
specific zone pairs represented by a particular combination of residence and workplace of an individual household. These variables measure the expected travel time from a specific residence to a specific workplace zone for each single-worker household. In addition, we incorporate a generalized accessibility to employment, to capture a range of access to services, retail, cultural amenities, and alternative employment locations.

Interactions of household characteristics with attributes of the alternatives are used to improve the sensitivity of the model to preferences that vary systematically over household characteristics. The most important one is the interaction of the household income with the cost of housing at a particular residential location, which reflects the affordability of housing for the household. If the model is well specified, this should be a strongly negative effect, indicating that, all else being equal, households prefer to spend a smaller fraction of their income on housing. We also include interactions between the size of the household making a location choice and the average household size in a neighborhood, to capture the tendency for small households to cluster, and larger, family households to cluster within neighborhoods. Finally, we include the interaction of household income with the quality of housing, as measured by the average improvement (building) value per residential unit. This measures the tendency for more affluent households to locate in neighborhoods where the quality of housing is higher.

The specification of the workplace choice equation is considerably more parsimonious, largely due to the limited information available about workers and workplace opportunities. We include the size of the opportunity set, as measured by the number of jobs in the workplace zone, and the transit and drive access times in the a.m. peak from residence to work.

Finally, the specification of the latent segmentation component includes a constant for the propensity to choose work location first, an indicator of the presence of children in the household, the household income, and the vehicle ownership of the household. We do not have strong priors on the direction of these effects, but expect them to be associated with the choice sequence.

\section{ESTIMATION RESULTS}

Estimation results are presented in Tables 2-5. First, a set of uni-directional choice models are presented. In Tables 2 and 3, we assume a single uni-directional choice sequence for the entire sample. The workplace choice model is estimated as though all households in the sample chose workplace conditional on a prior choice of residence. The residence choice model is estimated as though all households in the sample chose residence conditional on a prior choice of workplace.

The signs and significance of estimated parameters in these specifications is generally consistent with prior expectations. The accessibility variables for both transit and auto modes, in both the workplace and residence models, were negative and quite significant, though (as expected) the sensitivity to auto access was stronger on average, reflecting the predominance and superior performance of that mode of commuting. The number of jobs in a workplace destination was clearly the dominant variable in the workplace choice, as expected, although this is a somewhat underspecified model.

The next model we estimated was a joint model of residence, workplace, and latent choice structure. The results of this estimation, using all the variables entered in the independently estimated models, are shown in Table 4. We then refined this model by dropping insignificant variables, to produce the results in Table 5. Note that in the joint models we also include random parameters to reflect unobserved heterogeneity in preferences for certain attributes, such as auto travel time, and the cost to income ratio. There is a modest improvement 
in the log-likelihood of the joint model, which underlines the significance of identifying, probabilistically, the sequence of choosing residential and work locations. The results of the joint model are discussed below.

The latent segmentation model of choice sequence captured household effects on the propensity to choose workplace first. The estimation results confirm that there is a bias towards choosing residence first, and that children, income, and vehicle ownership all modify this average latent propensity. Households with more than one child are significantly inclined towards choosing residential location first, relative to other households. This is consistent with expectations that households with more children will be more likely to heavily consider the implications of schools on residence location, and given a particular residential choice, may be more tied to a residence location than would other households.

Households with higher income are more likely to choose their residential location first, relative to households with less income. This, although apparently counter intuitive, could be the manifestation of the fact that households with higher income choose to stay in affluent communities with high levels of amenities and relatively low property taxes. This would tend to reinforce the attachment to a residential location vis-à-vis the workplace.

Households with more than one car are more likely to choose their residential location first, relative to other households. Households with low vehicle ownership, especially in the oneworker sample we are studying, may be younger and lower-income than the average household in which case they are more likely to rent and to locate in housing that is relatively accessible to their workplace.

The basic pattern of results in this joint model was consistent with the uni-directional model of workplace choice (presented in Table 2). The higher the number of jobs in a zone, the more is the likelihood of the zone being chosen as the work place. And the travel times by auto and transit were again significant and in the expected direction, with the same pattern of larger relative magnitude of the auto travel time effect compared to transit. We added a random parameter to evaluate the effect of variation in drive time, but this coefficient was insignificant. Note that we constrained the travel time coefficients to be equal for the workplace and residence choice model component, since the commute travel times are a function of the combination of these two choices.

Again, the pattern of estimation results from the joint choice model was generally consistent with the uni-directional residential choice model (Table 3), although (as with the workplace choice model) the magnitude of the effects was affected, generally increasing the absolute value of the coefficients compared to the independent models. The magnitude increase in the coefficients is as expected, since the variance before scaling is larger in the independent MNL models compared to the joint latent segmentation model (22).

Interestingly, the coefficients on $\log$ (income) and population density, both significant in the uni-directional residential choice model shown in Table 3, became insignificant in the residential choice component of the joint model (see Table 4; the reader will also note that these statistically insignificant variables do not appear in the best specification of Table 5). The reduction in the significance of the t-statistics between the independent MNL models and the joint model was fairly consistent across the estimated parameters, in part due to the relative increase in the number of parameters to estimate as well as the introduction of a more complex discrete mixing structure with random parameters.

The scale parameter for the work location component of the joint model is substantially and significantly higher than unity. This indicates the larger error variance impacting work 
location relative to residential location (note that the scale parameter of the residential choice component of the joint model is normalized to 1 for identification). Thus, there is much more dispersion in residential choice-making among observationally identical households than there is dispersion in work place choice-making among observationally identical workers. This is not surprising, given the many subtle and intangible lifestyle and subjective preference issues that underlie residential choice decisions.

The aggregate shares of decision structures as derived from the latent choice model indicate that 80.8 percent of households choose residential location first, and then choose the work location conditional on the residential location. Less than 20 percent of the households choose the work location first. This contradicts the standard assumptions in much theoretical and empirical work in urban economics, but is consistent with empirical findings that the frequency of housing relocations is often lower than the frequency of job changes.

The coefficients in a complex choice model are not straightforward to directly interpret. We add, in Table 6, a set of computed elasticities that show the effects of several household characteristics on the latent segmentation shares. Note that the presence of multiple children significantly reduces the probability of making the workplace location choice first, as do increasing incomes, and owning multiple vehicles.

\section{CONCLUSIONS}

This paper has addressed an underdeveloped area of research on modeling the interdependence of residence and workplace. We have developed an approach to model the joint choices in a way that makes their estimation tractable, even for large-dimensioned choice sets, such as the nearly 1,000 residence and 1,000 workplaces represented in our data. The principal methodological innovation in the paper is the adaptation of a latent market segmentation approach to model the propensity to choose workplace or residence first. The jointly estimated model improved the log-likelihood ratio of the residence location model considerably, and of the workplace choice model modestly. This is because, in our empirical context, more than 80 percent of the households (workers) were found to choose residence first and then choose workplace conditional on residential location. As the uni-dimensional workplace choice model (which assumes that workplace is chosen conditional on residential location for the entire sample) is appropriate for a vast majority of households in the sample, the improvement in fit is rather modest relative to the improvement in the residential location choice model (which assumes the workplace location is chosen first). More importantly, it improves the capacity to represent a plausible substitution pattern among choice outcomes when the availability or attributes of residential alternatives or workplace alternatives changes.

Although the current model was estimated with single-worker households, it can be extended in a direct way to deal with multiple-worker households where a choice dimension is added for each additional worker's workplace. However, with each additional choice dimension, the computational complexity rises substantially and further methodological innovations are needed to tackle this challenge. We also did not attempt to address the problems associated with dynamic choices over time, as this would have added further complexity to the current research. Such an extension is also left for future research. Finally, it is noteworthy that this research used the TAZ as the spatial unit of choice. We did not analyze the implications of using this spatial unit for residence and workplace location choices, and must also defer to future research for a more thorough treatment of this topic. 
The research confirms that residence and workplace choices are interdependent and that a mixture of decision hierarchies or sequences may be present in the population. Ignoring this interdependence and population heterogeneity may bias policy analysis where residence and workplace choices are involved. The finding that more than 80 percent of the population chooses residential location first and then chooses the workplace location conditional on the residential location runs counter to the vast body of literature that often considers the workplace location to be exogenous to residential location choice. It would be interesting to see if similar results are obtained in other empirical contexts, both in the United States and other countries, to gauge the extent to which model findings of this nature are transferable across contexts. This finding has important implications for the specification and application of integrated land use activity-based travel demand models in which the sequencing of the residential and workplace location choices is often a critical component.

\section{ACKNOWLEDGMENT}

This research has been funded in part by National Science Foundation Grants IIS-0534094 and EIA-0121326, and by Environmental Protection Agency Grant R831837. The authors thank four anonymous referees for their constructive comments and suggestions to improve the paper.

\section{REFERENCES}

(1) Alonso, W. Location and Land Use. Harvard University Press, Cambridge, Massachusets, 1964

(2) Mills, E. and B. Hamilton. Urban Economics, 4th ed. Scott, Foresman, and Company, Glenview, Illinois, 1989.

(3) Putman, S. H. Integrated Urban Models. Pion Limited, London, 1983.

(4) Kain, J. F. and W. C. Apgar. Housing and Neighborhood Dynamics: A Simulation Study. Cambridge, Massachusets: Harvard University Press, 1985.

(5) Anas, A. Residential Location Markets and Urban Transportation: Economic Theory, Econometrics, and Policy Analysis with Discrete Choice Models. Academic Press: New York, 1982.

(6) de la Barra, T. Integrated Land Use and Transport Modelling. Cambridge: Cambridge University Press, 1989.

(7) Echenique, M., A.D.J. Flowerdew, J.D. Hunt, T.R. Mayo, I. Skidmore and D. Simmonds. The MEPLAN Models of Bilbao, Leeds, and Dortmund. Transport Reviews, Vol. 10, 1990, pp. 309-332.

(8) Waddell, P. UrbanSim: Modeling Urban Development for Land Use, Transportation and Environmental Planning. Journal of the American Planning Association, Vol. 68, No. 3, 2002, 297-314.

(9) Linneman, P. and P. Graves. Migration and Job Change: A Multinomial Logit Approach. Journal of Urban Economics, Vol. 14, 1983, pp. 263-279.

(10) Gordon, I. And R. Vickerman. Opportunity, Preference, and Constraint: An Approach to the Analysis of Metropolitan Migration. Urban Studies, Vol. 19, 1982, pp. 247-261.

(11) Siegel, J. Intrametropolitan Migration: A Simultaneous Model of Employment and Residential Location of White and Black Households. Journal of Urban Economics, Vol. 2, 1975, pp. 29-47.

(12) Simpson, W. A Simultaneous Model of Workplace and Residential Location Incorporating Job Search. Journal of Urban Economics, Vol. 8, 1980, pp. 330-349. 
(13) Simpson, W. Workplace Location, Residential Location, and Urban Commuting. Urban Studies, Vol. 24, 1987, pp. 119-128.

(14) Merriman, D. Compensation for Commutes in the Land and Labor Markets: Some Evidence from the Tokyo Metropolitan Area. Journal of Regional Science, Vol. 34, No. 3, 1994, pp. 297-324.

(15) Waddell, P. Exogenous Workplace Choice in Residential Location Models: Is the Assumption Valid? Geographical Analysis, Vol. 25, No. 1, 1993, pp. 65-82.

(16) Waddell, P. The Interdependence of Residential and Workplace Choice: Implications of Multiple Worker Households for Residential Mobility and Location Choice, 42nd Annual Meetings of the North American Regional Science Association International, Cincinnati, Ohio, 1995.

(17) Waddell, P. Accessibility and Residential Location: The Interaction of Workplace, Housing Tenure, Residential Mobility and Location Choices. In J. Preston, F. Pagliara, and D. Simmonds (eds) Modelling Residential Location Choice, Ashgate, Hampshire, UK, 2007, (forthcoming).

(18) Abraham, J.E. and Hunt, J.D. Specification and Estimation of Nested Logit Model of Home, Workplaces, and Commuter Mode Choice by Multiple Worker Households. Transportation Research Record 1606. TRB, National Research Council, Washington, D.C., 1997, pp. 1724.

(19) Freedman, O. and C.R. Kern. A Model of Workplace and Residence Choice Location in Two-worker Households. Regional Science and Urban Economics, Vol. 27, 1997, pp. 241260.

(20) Clark, W.A.V. and S. Withers. Changing Jobs and Changing Houses: Mobility Outcomes of Employment Transitions. Journal of Regional Science, Vol. 39, No. 4, 1999, pp. 653673.

(21) van Ommeren, J., P. Rietveld, and P. Nijkamp. Job Moving, Residential Moving, and Commuting: A Search Perspective. Journal of Urban Economics, Vol. 46, 1999, pp. 230253.

(22) Bhat, C.R. Econometric Choice Formulations: Alternative Model Structures, Estimation Techniques, and Emerging Directions, in K. Axhausen (ed) Moving Through Nets: The Physical and Social Dimensions of Travel, Elsevier, Oxford, 2007 (in press).

(23) Bhat, C.R., and J.Y. Guo. A Mixed Spatially Correlated Logit Model: Formulation and Application to Residential Choice Modeling. Transportation Research Part B, Vol. 38, No. 2, 2004, pp. 147-168.

(24) Hunt, L.M., Boots, B., and P.S. Kanaroglou. Spatial Choice Modelling: New Opportunities to Incorporate Space into Substitution Patterns. Progress in Human Geography, Vol. 28, No. 6, 2004, pp. 746-766.

(25) Nerella, S., and C.R. Bhat. Numerical Analysis of Effect of Sampling of Alternatives in Discrete Choice Models. Transportation Research Record 1894, TRB, 2004, pp. 11-19.

(26) Bhat, C.R. An Endogenous Segmentation Mode Choice Model with an Application to Intercity Travel. Transportation Science, Vol. 31, 1997, pp. 34-48.

(27) Greene, W.H., and D.A. Hensher. A Latent Class Model for Discrete Choice Analysis: Contrasts with Mixed Logit. Transportation Research Part B, Vol. 37, No. 8, 2003, pp. 681-698. 
(28) Bhat, C.R., T. Frusti, H. Zhao, S. Schonfelder, and K.W. Axhausen. Intershopping Duration: An Analysis Using Multiweek Data. Transportation Research Part B, Vol. 38, 2004, pp. 39-60.

(29) Gupta, S. and P.K. Chintagunta. On Using Demographic Variables to Determine Segment Membership in Logit Mixture Models. Journal of Marketing Research, Vol. 31, 1994, pp. 128-136.

(30) McFadden, D. Conditional Logit Analysis of Qualitative Choice Behaviour. Institute of Urban and Regional Development, University of California, Berkeley, California, 1973. 


\section{LIST OF TABLES}

TABLE 1 Household Characteristics of the One-Worker Household Sample

TABLE 2 Work Location Model (Residential Location fixed)

TABLE 3 Residential Location Model (Work Location fixed)

TABLE 4 Latent Segmentation Model of Work/Residential Location (All Variables in Tables 2 and 3 Retained)

TABLE 5 Latent Segmentation Model of Work/Residential Location (Best Specification)

TABLE 6 Elasticity Effects on the Latent Segmentation Shares 
TABLE 1 Household Characteristics of the One-Worker Household Sample

\begin{tabular}{ll}
\hline Characteristic & Sample Shares \\
\hline Sample Size & 1823 \\
\hline Household Size & \\
1 person & $41.1 \%$ \\
2 persons & $25.2 \%$ \\
3 persons & $14.7 \%$ \\
4 persons & $11.9 \%$ \\
$\geq 5$ persons & $7.1 \%$ \\
\hline Household Income (US Dollars) & \\
$<30,000$ & $29.3 \%$ \\
$30,000-50,000$ & $36.1 \%$ \\
$50,000-70,000$ & $25.6 \%$ \\
$>70,000$ & $9.0 \%$ \\
\hline Vehicle Ownership & \\
0 auto & $4.2 \%$ \\
1 auto & $42.2 \%$ \\
2 autos & $38.8 \%$ \\
3 autos & $9.4 \%$ \\
$\geq 4$ autos & $5.4 \%$ \\
\hline Children & \\
0 Children & $65.2 \%$ \\
1 Child & $14.3 \%$ \\
2 Children & $13.5 \%$ \\
\hline & $7.0 \%$ \\
\hline
\end{tabular}


TABLE 2 Work Location Model (Residential Location fixed)

\begin{tabular}{l|c|c}
\hline Variables & Coefficient & t-stat \\
\hline Neighborhood Attributes & 0.905 & 40.62 \\
Log (Number of Jobs) & & \\
\hline Accessibility & -0.663 & -9.47 \\
AM HW total transit/walk travel time (in 00's of minutes) & -0.651 & -26.31 \\
AM HW drive alone travel time (in tens of minutes) & \multicolumn{2}{|c}{-12476.2} \\
\hline Log-likelihood at zero & \multicolumn{2}{|c}{-9555.9} \\
Log-likelihood at convergence & \multicolumn{2}{|c}{0.234} \\
Likelihood Ratio Index & \\
\hline
\end{tabular}


TABLE 3 Residential Location Model (Work Location fixed)

\begin{tabular}{|c|c|c|}
\hline Variables & Coefficient & t-stat \\
\hline \multicolumn{3}{|l|}{ Neighborhood Attributes } \\
\hline Log (Number of jobs per acre) & -0.023 & -0.76 \\
\hline Log (Average Income) & 0.299 & 3.13 \\
\hline Log (Number of Residential Units) & 1.107 & 18.70 \\
\hline Log (Population per Acre) & -0.184 & -4.35 \\
\hline \multicolumn{3}{|l|}{ Accessibility } \\
\hline AM HW total transit/walk travel time (in 00 's of minutes) & -0.693 & -9.37 \\
\hline AM HW drive alone travel time (in tens of minutes) & -0.626 & -22.56 \\
\hline $\begin{array}{l}\text { Employment within } 30 \text { minutes } \mathrm{x} \\
\text { Log (AM HW drive alone travel time) }\end{array}$ & -0.409 & -19.45 \\
\hline \multicolumn{3}{|l|}{ Interactions of Household and Alternative Attributes } \\
\hline Persons x Average HH size & 0.284 & 9.98 \\
\hline Cost to Income ratio $\times 10^{-2}$ & -0.169 & -5.43 \\
\hline Income $\times 10^{-8} \times \log$ (Improvement Value per unit) & 0.191 & 6.64 \\
\hline Log-likelihood at zero & \multicolumn{2}{|c|}{-12476.2} \\
\hline Log-likelihood at convergence & \multicolumn{2}{|c|}{-10512.4} \\
\hline Likelihood Ratio Index & \multicolumn{2}{|c|}{0.157} \\
\hline
\end{tabular}


TABLE 4 Latent Segmentation Model of Work/Residential Location (All Variables in Tables 2 and 3 Retained)

\begin{tabular}{|c|c|c|}
\hline Variables & Coefficient & t-stat \\
\hline \multicolumn{3}{|l|}{$\begin{array}{l}\text { Latent Segmentation Component } \\
\text { Propensity to choose Work Location First } \\
\text { (Propensity to choose the Residential Location First is base) }\end{array}$} \\
\hline Constant & -0.648 & -3.54 \\
\hline $\begin{array}{l}\text { Household Attributes } \\
\text { No. of Children }>1 \text { (No. of Children } \leq 1 \text { is base) }\end{array}$ & -0.567 & -1.39 \\
\hline $\begin{array}{l}\text { Income in } 000 \text { 's of dollars }(<30 \text { is base }) \\
30-50 \\
50-70 \\
>70\end{array}$ & $\begin{array}{l}-0.374 \\
-0.863 \\
-1.987\end{array}$ & $\begin{array}{l}-1.59 \\
-2.76 \\
-2.49\end{array}$ \\
\hline $\begin{array}{l}\text { Vehicle Ownership } \\
\text { No. of Cars }>1 \text { ( No. of Cars } \leq 1 \text { is base ) }\end{array}$ & -0.588 & -2.52 \\
\hline \multicolumn{3}{|l|}{ Work Location Component } \\
\hline $\begin{array}{c}\text { Workplace Attributes } \\
\text { Log (Number of Jobs) }\end{array}$ & 1.899 & 11.78 \\
\hline $\begin{array}{l}\text { Accessibility } \\
\text { AM HW total transit/walk travel time (in 00's of minutes) } \\
\text { AM HW drive alone travel time (in tens of minutes) } \\
\text { Standard deviation on AM HW drive alone travel time }\end{array}$ & $\begin{array}{r}-0.947 \\
-1.097 \\
0.150\end{array}$ & $\begin{array}{l}-7.72 \\
-10.79 \\
1.07\end{array}$ \\
\hline \multicolumn{3}{|l|}{ Residential Location Component } \\
\hline $\begin{array}{l}\text { Neighborhood Attributes } \\
\text { Log (Number of jobs per acre) } \\
\text { Log (Average Income) } \\
\text { Log (Number of Residential Units) } \\
\text { Log (Population per Acre) }\end{array}$ & $\begin{array}{r}0.031 \\
0.279 \\
2.376 \\
-0.164\end{array}$ & $\begin{array}{r}0.29 \\
0.65 \\
8.78 \\
-0.83\end{array}$ \\
\hline $\begin{array}{l}\text { Accessibility } \\
\text { AM HW total transit/ walk travel time (in 00's of minutes) } \\
\text { AM HW drive alone travel time (in tens of minutes) } \\
\text { Standard deviation on AM HW drive alone travel time } \\
\text { Employment within } 30 \text { minutes x } \\
\quad \text { Log (AM HW drive alone travel time) }\end{array}$ & $\begin{array}{r}-0.947 \\
-1.097 \\
0.150 \\
-0.410\end{array}$ & $\begin{array}{c}-7.72 \\
-10.79 \\
1.07 \\
-3.03\end{array}$ \\
\hline $\begin{array}{l}\text { Interactions of Household and Alternative Attributes } \\
\left.\text { Cost to Income ratio ( } \times 10^{-2}\right) \\
\text { Standard Deviation on Cost to Income ratio } \\
\text { Income x } 10^{-8} \times \text { Log (Improvement Value per unit) } \\
\text { Persons x Average HH size }\end{array}$ & $\begin{array}{r}-0.846 \\
0.410 \\
-0.562 \\
0.424\end{array}$ & $\begin{array}{r}-2.96 \\
1.52 \\
-2.98 \\
2.96\end{array}$ \\
\hline $\begin{array}{l}\text { Scaling parameter corresponding to the Work Location } \\
\text { Component (Residential Location Component scale }=1 \text { ) }\end{array}$ & 1.725 & 11.98 \\
\hline $\begin{array}{l}\text { Log-likelihood at zero } \\
\text { Log-likelihood at Convergence for the joint model } \\
\text { Likelihood Ratio Index }\end{array}$ & $\begin{array}{r}-124 \\
-94 \\
0.2 \\
\end{array}$ & \\
\hline
\end{tabular}


TABLE 5 Latent Segmentation Model of Work/Residential Location (Best Specification)

\begin{tabular}{|c|c|c|}
\hline Variables & Coefficient & t-stats \\
\hline \multicolumn{3}{|l|}{$\begin{array}{l}\text { Latent Segmentation Component } \\
\text { Propensity to choose Work Location First } \\
\text { (Propensity to choose the Residential Location First is base) }\end{array}$} \\
\hline Constant & -0.637 & -3.47 \\
\hline $\begin{array}{l}\text { Household Attributes } \\
\text { No. of Children }>1 \text { (No. of Children } \leq 1 \text { is base) }\end{array}$ & -0.572 & -1.38 \\
\hline $\begin{array}{l}\text { Income in 000's of dollars }(<30 \text { is base }) \\
\quad 30-50 \\
50-70 \\
>70\end{array}$ & $\begin{array}{l}-0.393 \\
-0.940 \\
-2.210\end{array}$ & $\begin{array}{l}-1.67 \\
-2.94 \\
-2.58\end{array}$ \\
\hline $\begin{array}{l}\text { Vehicle Ownership } \\
\text { No. of Cars }>1 \text { ( No. of Cars } \leq 1 \text { is base ) }\end{array}$ & -0.600 & -2.56 \\
\hline \multicolumn{3}{|l|}{ Work Location Component } \\
\hline $\begin{array}{l}\text { Workplace Attributes } \\
\text { Log (Number of Jobs) } \\
\end{array}$ & 1.881 & 11.85 \\
\hline $\begin{array}{l}\text { Accessibility } \\
\text { AM HW total transit/walk travel time (in 00's of minutes) } \\
\text { AM HW drive alone travel time (in tens of minutes) } \\
\text { Standard deviation on AM HW drive alone travel time }\end{array}$ & $\begin{array}{r}-0.947 \\
-1.089 \\
0.144 \\
\end{array}$ & $\begin{array}{r}-7.77 \\
-10.83 \\
0.997 \\
\end{array}$ \\
\hline \multicolumn{3}{|l|}{ Residential Location Component } \\
\hline $\begin{array}{l}\text { Neighborhood Attributes } \\
\text { Log (Number of Residential Units) }\end{array}$ & 2.236 & 9.98 \\
\hline $\begin{array}{l}\text { Accessibility } \\
\text { AM HW total transit/walk travel time (in 00's of minutes) } \\
\text { AM HW drive alone travel time (in tens of minutes) } \\
\text { Standard deviation on AM HW drive alone travel time } \\
\text { Employment within } 30 \text { minutes x } \\
\quad \text { Log (AM HW drive alone travel time) }\end{array}$ & $\begin{array}{r}-0.947 \\
-1.089 \\
0.144 \\
-0.396\end{array}$ & $\begin{array}{r}-7.77 \\
-10.83 \\
0.997 \\
-3.26\end{array}$ \\
\hline $\begin{array}{l}\text { Interaction of Household and Alternative Attributes } \\
\text { Cost to Income ratio }\left(\mathrm{x} 10^{-2}\right) \\
\text { Standard Deviation on Cost to Income ratio } \\
\text { Income x } 10^{-8} \text { x Log (Improvement Value per unit) } \\
\text { Persons x Average HH size }\end{array}$ & $\begin{array}{r}-0.670 \\
0.341 \\
0.616 \\
0.403\end{array}$ & $\begin{array}{r}-3.30 \\
1.43 \\
3.34 \\
2.99 \\
\end{array}$ \\
\hline $\begin{array}{l}\text { Scaling parameter corresponding to the Work Location } \\
\text { Component (Residential Location Component scale = 1) }\end{array}$ & 1.715 & 12.04 \\
\hline $\begin{array}{l}\text { Log-likelihood at zero } \\
\text { Log-likelihood at Convergence for the joint model } \\
\text { Likelihood Ratio Index }\end{array}$ & $\begin{array}{r}-124 \\
-94 \\
0.2\end{array}$ & \\
\hline
\end{tabular}


TABLE 6 Elasticity Effects on the Latent Segmentation Shares

\begin{tabular}{l|c|c}
\hline \multirow{2}{*}{ Variables } & \multicolumn{2}{|c}{ Elasticity Effects } \\
\cline { 2 - 3 } & $\begin{array}{c}\text { Work } \\
\text { Location First }\end{array}$ & $\begin{array}{c}\text { Residence } \\
\text { Location First }\end{array}$ \\
\hline Household Attributes & -38.2 & 9.1 \\
No. of Children $>1$ (No. of Children $\leq 1$ is base) & & \\
\hline Income in 000's of dollars (<30 is base) & -29.2 & 7.0 \\
$30-50$ & -62.7 & 14.9 \\
$50-70$ & -93.6 & 22.3 \\
$>70$ & & \\
\hline Vehicle Ownership & -45.6 & 10.9 \\
$\quad$ No. of Cars $>1$ ( No. of Cars $\leq 1$ is base ) &
\end{tabular}

